\title{
Application Of Web-Based Industrial Environment Test Results
}

\section{Aplikasi Pengolahan Hasil Uji Lingkungan Industri Berbasis Web}

\author{
Muhammad Jamilul Iman, Mochamad Alfan Rosid \\ [mjamiluliman@gmail.com, 2alfanrosid@umsida.ac.id]
}

Program Studi Informatika, Universitas Muhammadiyah Sidoarjo, Indonesia

\begin{abstract}
Tests on an industrial environment is needed to ensure the health and as a way to combat pollution in the surrounding environment. To obtain data and information about the content of chemical substances that exist in the region need of good accuracy in order to provide accurate research results. If the process using the manual method, it will take a long time to make a report of the information obtained. As for the various samples taken have different standards or methods based on government regulations. The application for processing the results of industrial environment test uses the PHP programming language and uses a MySQL database. Application uses the Black Box method from display to input action. Moreover,testing this application using a Likert scale, the author gives a questionnaire to the marketing of 5 people and laboratory 5 people with questions about the appearance results of input and output application with 5 items. The results of this test, the application of industrial environmental results can be accepted by laboratory application with a percentage of $74.4 \%$. This laboratory application helps data management and administration PT. Xyz, becomes temporary information or the final report on the evaluation of research conducted.
\end{abstract}

Keywords - Information System; Environmental Test Results; Environmental Laboratory; Web Application

\begin{abstract}
Abstrak. Pengujian terhadap suatu lingkungan industri sangat diperlukan untuk menjamin kesehatan dan sebagai cara untuk menanggulangi polusi di sekitar lingkungan tersebut. Untuk mendapatkan data dan informasi seputar kandungan dari zat kimia yang ada pada daerah tersebut membutuhkan ketelitian yang baik agar memberikan hasil penelitian yang sangat akurat. Jika dalam pengerjaannya masih menggunakan cara manual, akan membutuhkan waktu lama untuk membuat laporan dari informasi yang didapat. Sedangkan untuk berbagai sampel yang diambil mempunyai standar atau metode yang berbeda berdasarkan peraturan dari pemerintah. Aplikasi pengolahan hasil uji lingkungan industri berbasis web ini dalam pembuatannya menggunakan bahasa pemrograman PHP dan menggunakan database MySQL. Aplikasi ini menggunakan metode Black Box dalam pengujian tampilan serta inputannya. Selain itu pengujian aplikasi ini dengan menggunakan Skala likert yakni penulis memberikan kuisioner kepada marketing 5 orang dan petugas laboratorium 5 orang dengan pertanyaan mengenai tampilan dan hasil input output aplikasi sebanyak 5 butir. Hasil yang di dapatkan dari pengujian skala likert, aplikasi pengolahan hasil uji lingkungan indusri ini dapat diterima atau layak sebagai aplikasi laboratorium dengan persentase 74,4\%. Aplikasi laboratorium ini membantu manajemen data dan administrasi di laboratorium PT. Xyz, serta menjadi informasi sementara atau laporan akhir evaluasi penelitian yang dilakukan.
\end{abstract}

Kata Kunci - Sistem Informasi; Hasil Uji Lingkungan; Laboratorium Lingkungan; Aplikasi Web

\section{Pendahuluan}

\section{A. Latar Belakang}

Saat ini ini di dunia industri semakin berkembang teknologi yang diciptakan, Hal ini membuat Instansi atau perusahaan harus mampu memanajemen semua data dan informasi yang berguna bagi perusahaan itu sendiri. Salah satu perusahaan yang sangat dituntut untuk memberikan informasi yang tepat dan akurat adalah laboratorium. Upaya perbaikan kesehatan masyarakat dapat dilakukan melalui berbagai macam cara, yaitu pencegahan dan pemberantasan penyakit menular, penyehatan lingkungan, penyediaan air bersih, serta penyuluhan kesehatan. Selain itu, perlindungan terhadap bahaya pencemaran lingkungan juga perlu diberikan perhatian lebih. Semua upaya tersebut tidak lain bertujuan untuk meningkatkan derajat kesehatan masyarakat (Notoatmojo S, 2007).

Suatu laboratorium akan semakin mendapat kepercayaan dari berbagai pihak jika bisa memberikan laporan yang cepat namun tidak mengesampingkan ketepatan dan keakuratan dari hasil uji atau penelitan yang telah dilakukan. Kegunaan sistem informasi manajemen adalah salah satu hal yang wajib diperhitungkan dalam mengatasi masalah pengelolaan informasi. Sistem informasi manajemen sendiri merupakan suatu serapan teknologi baru untuk permasalahan keorganisasian dalam pengolahan transaksi dan pemberian informasi bagi kepentingan keorganisasian (Davis,1985).

Sebagai perusahaan yang bergerak di bidang laboratorium lingkungan, PT. Xyz banyak mendapatkan proyekproyek penelitian dari berbagai perusahaan atau instansi lain. Meskipun demikian, jika pembuatan laporan masih 
menggunakan cara manual atau dibuat menggunakan program spreedsheet, maka akan sangat merepotkan dan membutuhkan waktu yang lama, karena dirasa kurang efektif dan efeisien. Oleh karena itu, pada perusahaan ini dibutuhkan sebuah sistem informasi yang dapat digunakan untuk mengelola proyek-proyek penelitian yang ada, mulai dari perencanaan, pemasaran, pengujian, bahkan sampai pada proses dokumentasi penelitian agar didapatkan hasil akhir yang baik dan meningkatkan profesionalisme perusahaan dalam menangani sebuah proyek. Selain itu, dengan dibuatnya aplikasi ini menggunakan Framework PHP diharapkan dapat lebih fokus pada alur bisnis dari sistem informasi yang dikerjakan, sehingga akan menghasilkan aplikasi sistem informasi yang lebih baik, bisa diakses dari mana saja karena tidak perlu melakukan instalasi khusus pada komputer, dan juga akan mempermudah pengelolaan data karena semua data disimpan secara terpusat pada sebuah server.

\section{B. Kajian Literatur Terdahulu}

Table 1. Kajian literature Terdahulu

\begin{tabular}{|c|c|c|c|}
\hline Nama & Tahun & Judul & Hasil \\
\hline Relaci Aprilia & \multirow{7}{*}{2017} & \multirow{2}{*}{$\begin{array}{c}\text { Bangun Sistem } \\
\text { Laboratorium }\end{array}$} & Laboratorium \\
\hline \multirow[t]{6}{*}{ Istiqomah } & & & Lingkungan ini \\
\hline & & Lingkungan & membangkitkan baku \\
\hline & & Pelaksana & parameter berdasarkan jenis sampel \\
\hline & & Laboratorium Lingkungan & yang dipilih. \\
\hline & & Dinas Lingkungan Hidup & \\
\hline & & Provinsi Jawa Timur & \\
\hline \multirow[t]{6}{*}{ Nur Azizah } & \multirow[t]{6}{*}{2018} & Pelayanan & Prosedur \\
\hline & & Masyarakat & masyarakat pada Dinas Lingkungan \\
\hline & & Pencemaran & Hidup dan Kebersihan Kabupaten \\
\hline & & Pada Dinas & digambarkan \\
\hline & & Hidup Dan Kebersihan & menggunakan diagram UML (Unified \\
\hline & & Kabupaten Tangerang & Modeling Language \\
\hline
\end{tabular}

Penelitian sekarang yaitu Aplikasi Pengolahan Hasil Uji Lingkungan Industri Berbasis Web PT Xyz dengan metode pengumpulan data yang dilakukan denganwawancara dan observasi. Perancangan menggunakan database MySQL dan bahasa pemprograman PHP.

\section{Tujuan Kajian Artikel}

Adapun tujuan dibuatnya artikel ini adalah membuat sebuah sistem untuk memonitor pekerjaan di laboratorium PT. Xyz atau beberapa hal yang berhubungan dengan proses pengolahan data, seperti membuat surat penawaran, surat perintah kerja, mencatat sample, mencatat regulatory testing, sampai dengan membuat laporan akhir dari hasil uji lingkungan industri yang telah dilakukan.

\section{METODE}

\section{A. Alat dan Bahan}

Adapun perangkat yang digunakan dalam penelitian ini :

a. Perangkat Keras :

1. Laptop Asus Processor Core i5 8th Gen

2. $8 \mathrm{~Gb}$ Ram

3. $1 \mathrm{~Tb}$ Hdd

4. Vga Nvidia Geforce 930MX

5. Perangkat Mouse Standar

b. Perangkat Lunak :

1. Xampp Control Panel

2. Text editor Notepad++

3. Php Yii sebagai Bahasa web pemrograman

4. Browser Chrome

\section{B. Metode pengumpulan data}

Untuk mendapatkan data guna perancangan sistem yang akan dibuat maka penulis melakukan dua metode yakni data primer yaitu pengumpulan data menggunakan observasi dan wawancara ke pihak-pihak terkait serta dengan data sekunder yaitu cara mendapatkan data dengan mencari informasi dari berbagai sumber informasi . 


\section{Konteks diagram}

Pada proses perancangan sistem yang dikerjakan meliputi beberapa hal yakni analisa kebutuhan user yang sebelumnya didapatkan. Dari data kebutuhan user ini dapat ditentukan konsep, fitur, dan teknologi apa saja yang tepat untuk diterapkan nantinya.

Pada proses ini juga ditentukan bagaimana rancangan aplikasi, mulai dari alur aplikasi, rancangan database, dan jenis database apa yang akan digunakan, sampai pada rancangan interface awal dari aplikasi. Perancangan tersebut akan dijelaskan sebagai berikut :

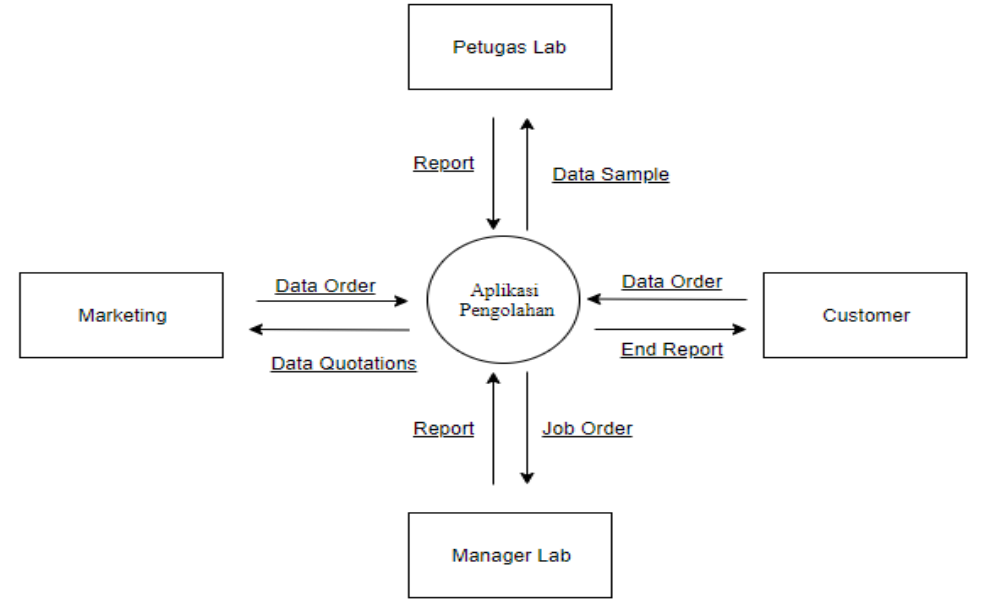

Gambar 1. Diagram Konteks Lingkungan PT. Xyz

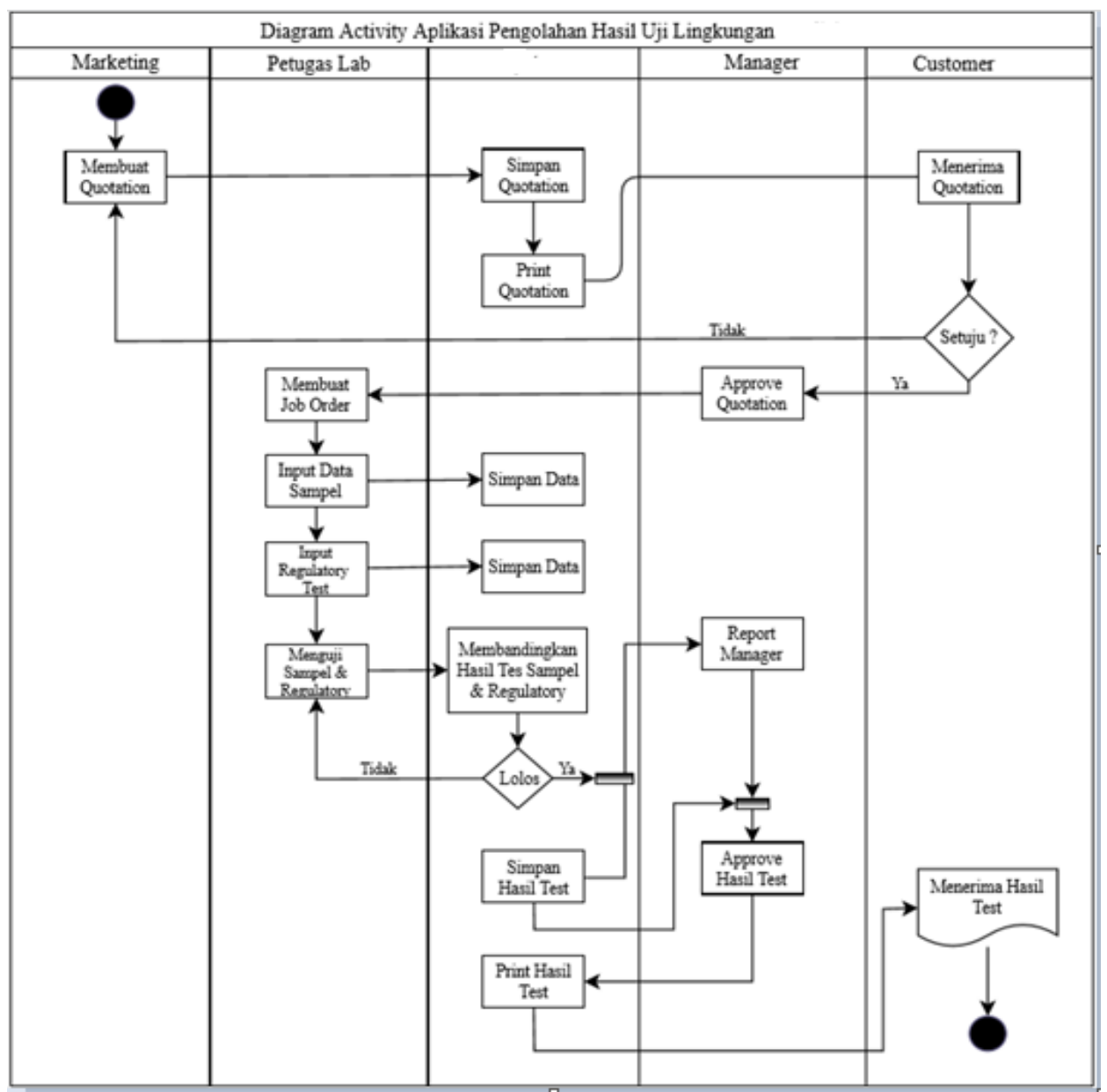

Gambar 2 Diagram Activity PT Xyz monitoring system 
Berdasarkan gambar 2 dapat dijelaskan proses atau alur kerja program sebagai berikut :

- Customer meminta penawaran proyek kepada Marketing PT. Xyz secara formal atau non-formal.

- Selanjutnya Marketing membuat penawaran untuk proyek tersebut dan dikirimkan lagi kepada Customer.

- Setelah Customer setuju, Marketing kemudian memberikan proyek tersebut kepada Supervisor Project / Manajer Laboratorium.

- Selanjutnya Supervisor Project / Manajer Laboratorium membuat job order untuk proyek tersebut.

- Petugas Lapangan / Sampling melakukan survey tempat dan mengambil beberapa sampel untuk diteliti di Laboratorium.

- Sampel yang diperoleh dari Petugas Lapangan / Sampling diproses oleh Petugas Laboratorium.

- Petugas Laboratorium memiliki data regulatory yang diperlukan untuk kepentingan penelitian / pengujian sampel.

- Setelah penelitian / pengujian sampel selesai, selanjutnya Petugas Laboratorium membuat laporan hasil uji tersebut.

- Laporan hasil uji tersebut diserahkan kepada Supervisor Project / Manajer Laboratorium untuk dievaluasi.

- Setelah semua proses selesai dan didapat laporan akhir hasil uji yang sudah dievaluasi oleh Supervisor Project / Manajer Laboratorium, laporan tersebut kemudian dikirimkan kepada pihak Customer bersangkutan.

\section{Metode Pengujian Aplikasi}

Pengujian system merupakan bagian yang sangat penting dalam membangun sebuah aplikasi. Pengujian dibutuhkan agar dapat mengetahui fungsional dan titik kesalahan aplikasi. Teknik yang akan digunakan yaitu Black Box. Pengujian blackbox berusaha menentukan Kesalahan Fungsi, interface tau struktur data berikut ini table pengujian :

Table 2. Rencana Pengujian sistem

\begin{tabular}{|c|c|c|}
\hline \multicolumn{3}{|c|}{ Pengujian Sistem } \\
\hline Item Pengujian & Deskripsi Pengujian & Jenis Pengujian \\
\hline Login & Mengisi data login & Black Box \\
\hline Tambah User & Menambah data user & Black Box \\
\hline Data Pelanggan & $\begin{array}{l}\text { Menghapus, Mengedit dan Menambahkan data } \\
\text { pelanggan yang baru }\end{array}$ & Black Box \\
\hline Data pengujian & $\begin{array}{l}\text { Menghapus, Mengedit dan Menambahkan data } \\
\text { Pengujian }\end{array}$ & Black Box \\
\hline
\end{tabular}

Selain Menggunakan metode Blackbox program aplikasi pengolahan hasil uji lingkungan Industri ini penulis juga menggunakan Skala Likert, yakni penulis memberi kuisioner untuk 10 responden yang terbagi dari marketing 5 orang dan petugas laboratorium 5 orang berikut ini adalah table pertanyaan kuisioner yang akan diberikan.

Table 3 Pertanyaan Kuisioner

\begin{tabular}{|c|c|c|c|c|c|c|}
\hline \multirow[b]{2}{*}{ No } & \multirow{2}{*}{ Pernyataan } & \multicolumn{5}{|c|}{ Skor } \\
\hline & & SS & $\mathrm{S}$ & CS & $\mathrm{TS}$ & STS \\
\hline 1 & Apakah anda setuju tampilan aplikasi ini cukup menarik & & & & & \\
\hline 2 & Apakah anda setuju aplikasi ini berfungsi dengan baik & & & & & \\
\hline 3 & $\begin{array}{l}\text { Apakah anda setuju pesan kesalahan yang muncul dapat } \\
\text { dimengerti }\end{array}$ & & & & & \\
\hline 4 & Apakah anda setuju dengan pemilihan warna aplikasi & & & & & \\
\hline 5 & $\begin{array}{l}\text { Apakah setuju aplikasi ini dapat membantu pekerjaan } \\
\text { anda }\end{array}$ & & & & & \\
\hline
\end{tabular}

\section{Hasil dan Pembahasan}

\section{A. Hasil Penelitian}

Pada Tahap ini setelah semua data dikumpulkan dapat diperoleh hasil penelitian berupa website sistem informasi menggunakan sebuah framework php Yii Framework. Tujuan sistem ini dirancang agar mempermudah semua petugas Laboratorium PT. Xyz dalam menginputkan data dan mencetak hasil pengujian, selain itu petugas juga dapat melihat hasil pengujian yang sudah dilakukan sebelumnya secara detail. Untuk menjalankan sistem ini dibutuhkan perangkat komputer. Pada pengujian ini penulis menggunakan perangkat laptop asus i5 64 Bit.

1. Sistem ini digunakan untuk menyimpan data hasil pengujian pada customer

2. Sistem ini memiliki 2 interface yaitu admin laboratorium dan marketing 
3. Interface admin laboratorium digunakan untuk mengelolah informasi tentang laporan hasil pengujian dan data hasil pengujian, mulai dari input, edit, tambah data dan hapus. Interface marketing untuk menginputkan data penawaran kepada customer.

4. Perbedaan ketiga interface akan terlihat saat login masuk kedalam sistem. Login sebagai admin laboratorium atau marketing.

\section{B. Pembahasan Sistem}

Menu Login merupakan menu yang menentukan teknisi mengakses sistem sebagai admin laboratorium atau Marketing. Dalam menu ini, teknisi diharuskan memasukkan username dan password. Berikut merupakan tampilan halaman menu login pada sistem.

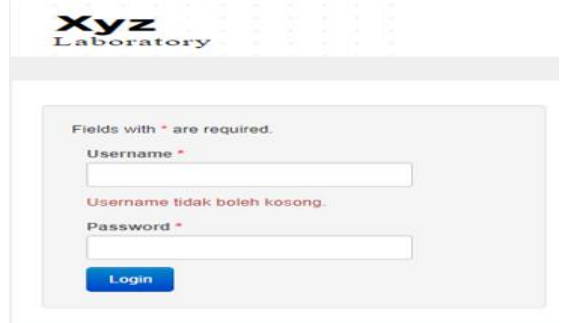

Gambar 3 Halaman Login

Menu utama merupakan halaman yang tampil setelah halaman login. Menu ini berfungsi untuk membuka fiturfitur yang terdapat dalam sistem. Berikut adalah menu yang ada pada user admin laboratorium yaitu project dan setup

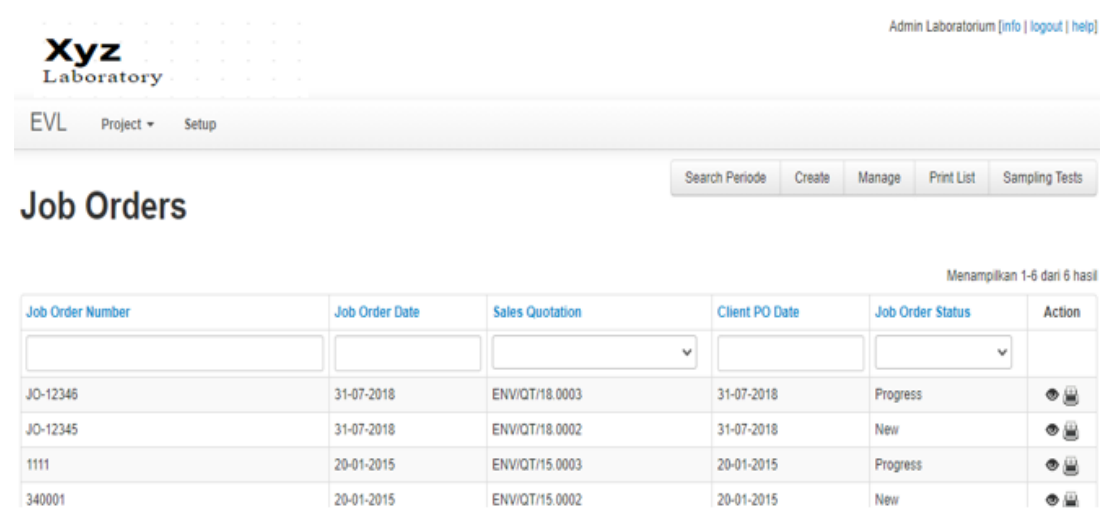

Gambar 4 Tampilan Menu Utama

Menu Project Job order merupakan menu yang berfungsi untuk menampilkan sekaligus membuat sebuah job order baru. Tampilan dibawah ini merupakan tampilan form input untuk membuat sebuah job order.

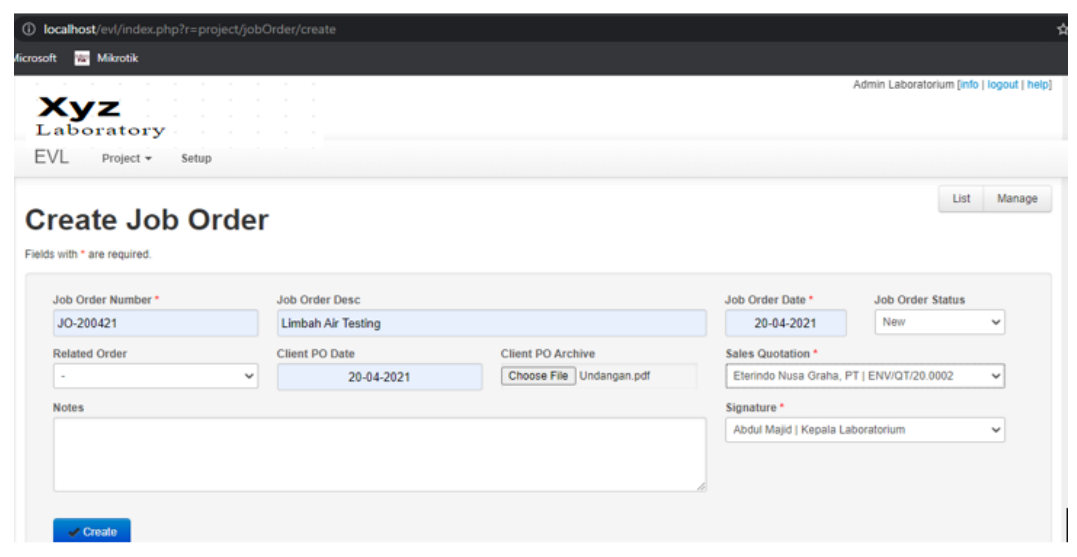

Gambar 5 Form Input Job Order 
Setelah mengisikan form job order maka admin laboratorium melakukan pengisian hasil pengujian. Berikut dibawah ini tampilan form input hasil pengujian laboratorium

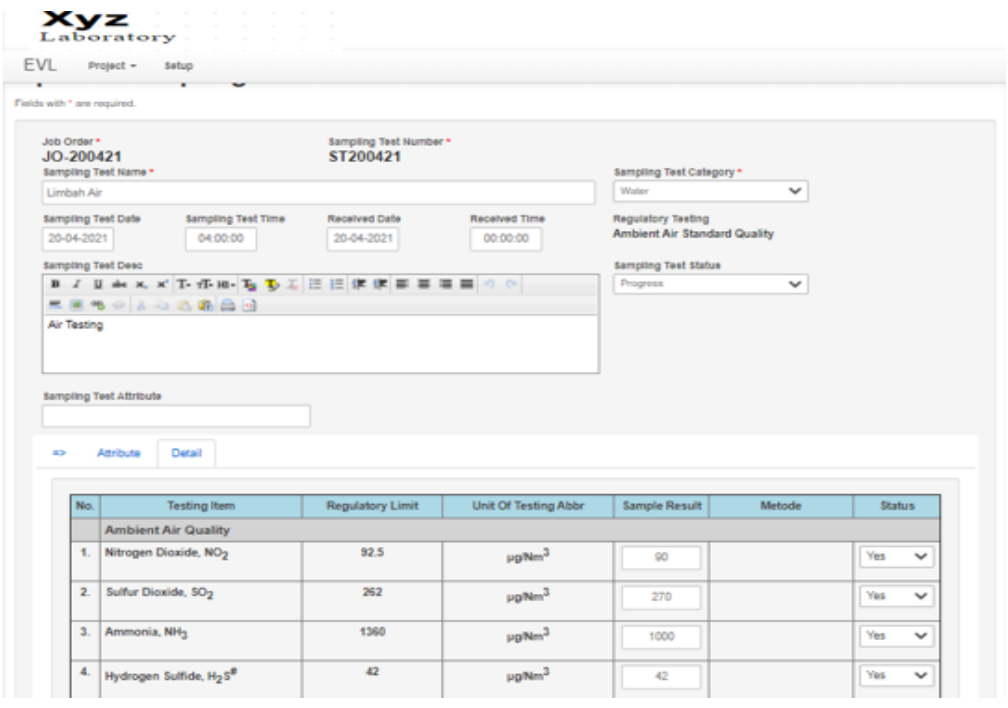

Gambar 6 Form Input Hasil Pengujian

Gambar dibawah ini merupakan lembar hasil cetak pdf yang akan diberikan kepada customer. Yang berisikan kolom Test deskripsi, sample pengujian batas standar, satuan dan metode yang digunakan untuk pengujian.

\section{Laboratory}

\begin{tabular}{|c|c|c|c|c|c|}
\hline \multicolumn{6}{|c|}{ LABORATORY TEST RESULTS } \\
\hline \multicolumn{5}{|c|}{ Job Number : JO-200421 } & Date : 20 April 2021 \\
\hline \multicolumn{5}{|c|}{ Customer : Eterindo Nusa Giraha, PT } & Attention : Ibu Farida \\
\hline \multicolumn{3}{|c|}{ Customer Sample ID $\quad$ : Limbah Air } & & \\
\hline \multirow{2}{*}{\multicolumn{2}{|c|}{$\begin{array}{l}\text { Date Sampled } \\
\text { Time Sampled }\end{array}$}} & $: 20-04-2021$ & & & $:$ ST200421 \\
\hline & & : 04:00:00 & \multicolumn{2}{|c|}{$\begin{array}{l}\text { Laboratory Sample ID } \\
\text { Date Received }\end{array}$} & $: 20-04-2021$ \\
\hline \multicolumn{2}{|r|}{ Sample Matrix } & Water & \multicolumn{2}{|c|}{ Time Received } & $: 00.00 \cdot 00$ \\
\hline Na. & TEST DESCRIPTION & $\begin{array}{l}\text { SAMPLE } \\
\text { RESULT }\end{array}$ & $\begin{array}{l}\text { REGULATORY } \\
\text { UMIT }\end{array}$ & UNIT & METHOD \\
\hline & \begin{tabular}{|l|} 
Ambient Air Quality \\
\end{tabular} & & & & \\
\hline 1. & Nitrogen Dioxide, NO2 & 90 & 92.5 & $? \mathrm{~g} / \mathrm{Nm}^{3}$ & \\
\hline 2. & Sulfur Dioxide, $\mathrm{SO} 2$ & 270 & 262 & $2 \mathrm{~g} / \mathrm{Nm}^{3}$ & \\
\hline 3. & Ammonia, NH3 & 1000 & 1360 & $? \mathrm{~g} / \mathrm{Nm} 3$ & \\
\hline 4. & Hydrogen Sulfide, H2S & 42 & 42 & $2 \mathrm{~g} / \mathrm{Nm}^{3}$ & \\
\hline 5. & Dust** & 260 & 260 & $\mathrm{um} / \mathrm{Nm}^{3}$ & \\
\hline 6. & Hydrocarbon, $\mathrm{HCH}$ & 180 & 160 & $? \mathrm{~g} / \mathrm{Nm} 3$ & \\
\hline 7. & Carbon Monoxide, $\mathrm{CO} \equiv$ & 22800 & 22600 & $2 \mathrm{~g} / \mathrm{Nm} 3$ & \\
\hline 8. & Oxidant, $\mathrm{O} 3$ & 190 & 200 & ?g/Nm3 & \\
\hline 9. & Lead, Pb** & 70 & 60 & $2 \mathrm{~g} / \mathrm{Nm} 3$ & \\
\hline 10. & Noiseff & & 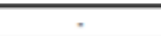 & $\mathrm{dBA}$ & \\
\hline
\end{tabular}

Gambar 7 Hasil Print Report

Setelah melakukan input data sampel admin laboratorium mencetak file menggunakan tombol print pada kolom action yang ada di menu sample tes dan akan muncul hasil output berupa pdf. Dari hasil Pengujian Jo-200421 diatas didapat bahwa jika Hasil sample result atau hasil pengujian melebihi dari regulatory limit atau batasan dari hasil pengujian jika sample yang dihasilkan melebihi dari batas regulatory limit maka dianggap sebagai limbah yang berbahaya.

\section{Pengujian Aplikasi}


Pengujian system merupakan bagian yang sangat penting dalam membangun sebuah aplikasi. Pengujian dibutuhkan agar dapat menjamin kualitas dan juga mengetahui kelemahan dari aplikasi. Disini peneliti menggunakan Teknik Black Box.

Table 4 Hasil Pengujian

\begin{tabular}{|c|c|c|c|}
\hline \multicolumn{4}{|c|}{ Kasus dan hasil uji (data benar) } \\
\hline Data masukan & Yang diharapkan & Pengamatan & Kesimpulan \\
\hline $\begin{array}{l}\text { 1. Pengujian Login } \\
\text { menggunakan } \\
\text { Username = lab } \\
\text { Password = lab }\end{array}$ & $\begin{array}{l}\text { Dapat terisi pada } \\
\text { form textfield } \\
\text { username dan } \\
\text { password, cek } \\
\text { data di database }\end{array}$ & $\begin{array}{l}\text { Dapat mengisi } \\
\text { username dan } \\
\text { password, } \\
\text { pengecekan } \\
\text { data di database } \\
\text { sesuai }\end{array}$ & [ ok ] diterima \\
\hline $\begin{array}{l}\text { 2. Admin } \\
\text { Laboratorium } \\
\text { Menginputkan data } \\
\text { job order dan nilai } \\
\text { dari hasil uji lab }\end{array}$ & $\begin{array}{l}\text { Dapat terisi pada } \\
\text { form textfield }\end{array}$ & $\begin{array}{l}\text { Data diterima dan } \\
\text { tersimpan kedalam } \\
\text { database. }\end{array}$ & [ ok ] diterima \\
\hline & Kasus dan hasil uji (d & ta salah) & \\
\hline $\begin{array}{l}\text { Data masukan } \\
\text { 1. Pengujian Login } \\
\text { menggunakan } \\
\text { Username = lab } \\
\text { Password= lab }\end{array}$ & $\begin{array}{l}\text { Yang diharapkan } \\
\text { Saat menekan } \\
\text { tombol login } \\
\text { tampil kesalahan, } \\
\text { karena data tidak } \\
\text { ada di database }\end{array}$ & $\begin{array}{l}\text { Pengamatan } \\
\text { Tampil pesan } \\
\text { kesalahan }\end{array}$ & $\begin{array}{l}\text { Kesimpulan } \\
\text { [ no ] ditolak }\end{array}$ \\
\hline
\end{tabular}

Dalam pengujian program aplikasi pengolahan hasil uji lingkungan Industri ini penulis juga menggunakan Skala Likert, yakni penulis memberi kuisioner untuk 10 responden yang terbagi dari marketing 5 orang dan petugas laboratorium 5 orang

Table 5 Pertanyaan Kuisioner

\begin{tabular}{|c|c|c|c|c|c|c|}
\hline \multirow[b]{2}{*}{ No } & \multirow{2}{*}{ Pernyataan } & \multicolumn{5}{|c|}{ Skor } \\
\hline & & SS & S & CS & TS & STS \\
\hline 1 & $\begin{array}{l}\text { Apakah anda setuju tampilan aplikasi ini } \\
\text { cukup menarik }\end{array}$ & & 6 & 4 & & \\
\hline 2 & $\begin{array}{l}\text { Apakah anda setuju aplikasi ini berfungsi } \\
\text { dengan baik }\end{array}$ & & 8 & 2 & & \\
\hline 3 & $\begin{array}{l}\text { Apakah anda setuju pesan kesalahan yang } \\
\text { muncul dapat dimengerti }\end{array}$ & & 7 & 3 & & \\
\hline 4 & $\begin{array}{l}\text { Apakah anda setuju dengan pemilihan warna } \\
\text { aplikasi }\end{array}$ & & 6 & 3 & 1 & \\
\hline 5 & $\begin{array}{l}\text { Apakah setuju aplikasi ini dapat membantu } \\
\text { pekerjaan anda }\end{array}$ & & 8 & 2 & & \\
\hline & Jumlah & 0 & 35 & 14 & 1 & 0 \\
\hline & Jumlah Skor & 0 & 140 & 42 & 4 & 0 \\
\hline & $\sum \mathrm{SKOR}$ & & & 186 & & \\
\hline & Persentase \% & & & 74,4 & & \\
\hline
\end{tabular}

Perhitungan dari table diatas jumlah didapatkan dari skor tiap butir pertanyaan yang dikalikan bobot skor yaitu SS(5), S(4), CS(3), TS(2), STS(1), skor maksimal yaitu skor tertinggi pada sekala likert yang dikalikan banyaknya butir soal $5 \times 5=25$. Jumlah skor diharapkan yaitu skor maksimal dikali jumlah responden $25 \times 10=250$, berikut rumus persentase dari data kuisioner:

$\sum$ skor $=($ jumlah $\mathrm{x}$ skor SS $)+($ jumlah $\mathrm{x}$ skor $\mathrm{S})+($ jumlah $\mathrm{x}$ skor $\mathrm{CS})+($ jumlah $\mathrm{x}$ skor TS $)+($ jumlah $\mathrm{x}$ skor STS $)$

$\sum$ skor $=(0 \times 5)+(35 \times 4)+(14 \times 3)+(1 \times 2)+(0 \times 1)$ 
$\sum$ skor $=186$

Untuk peresentase kelayakan data dari marketing dan petugas lab sebagai berikut :

Persentase $=\frac{\sum \text { Skor }}{\text { Skor diharapkan }} \times 100 \%$

Persentase $=\frac{186}{250} \times 100 \%$

Persentase $=74,4 \%$

Berdasarkan dari hasil persentase $74,4 \%$ dapat dikategorikan sebagai aplikasi pengolahan hasil uji lingkungan industri ini dapat diterima atau layak sebagai aplikasi laboratorium oleh marketing dan petugas laboratorium.secara garis besar dapat digambarkan untuk persentasenya sebagai berikut :

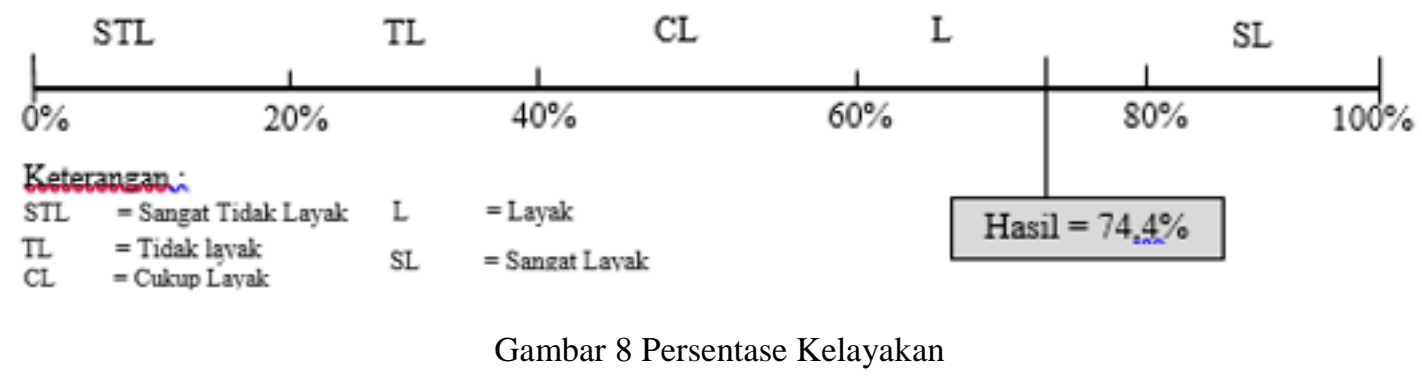

\section{KESIMPULAN}

Setelah merancang sistem informasi hasil uji lingkungan industri berbasis web php menggunakan YII framework dan sesuai dengan permasalahan yang ada di PT Xyz, maka dapat disimpulkan sebagai berikut : (1.) Inputan Login untuk setiap user sudah benar dan menampilkan menu user masing-masing. (2.)Data Yang diinputkan oleh admin lab dapat diterima sistem dan menghasilkan outputan yang benar (3.)Sistem informasi ini dapat mempermudah petugas lab dalam menginputkan data dan membantu menyelesaikan tugasnya dengan lebih efektif . (4.) Informasi data hasil uji laboratorium dari petugas lab langsung disimpan kedalam database.(5.) Laporan yang diminta via e-mail tidak lagi perlu discan, karena sudah bisa langsung save as pdf. Dari penelitian Aplikasi Pengolahan Hasil Uji Lingkungan Industry Berbasis Web ini penulis sadar akan banyaknya kekurangan. Karena hanya sedikit yang dapat diimplementasikan. Semoga dapat menjadikan penelitian ini menjadi lebih baik lagi dipengembangan penelitian selanjutnya.

\section{REFERENSI}

[1] Muhammad Irwan Effendi, ST (Juni,6/2016).Peranan Proper Dalam Peningkatan Kinerja Perusahaan Dalam Pengelolaan Lingkungan http://kepbabel.silh. menlh.go.id/ peranan-proper-dalam-peningkatan kinerjaperusahaan-dalam-pengelolaan-lingkungan/ diakses pada 20 oktober 2019

[2] Jeperson hutahaean. (2014). Konsep Sistem Informasi. Konsep Sistem Informasi (Vol. 53). https://doi.org/10.1017/CBO9781107415324.004 diakses pada 20 oktober 2019

[3] exabytes-id. (Dec, 25/2013). Fat Free Framework. http://www.phpindonesia.net/ artikel/mengenal-yiiframework Mengenal YII Frameworks Berbasis PHP diakses pada 1 Desember 2020

[4] Ejurnal, http://ejurnal.its.ac.id/index.php/teknik/article/viewFile/23741/4407 di Download pada 1 januari 2021

[5] Carawebs.info, "Cara Web," carawebs.info, 2017. [Online]. Available: http://www.carawebs.info/2013/04/apaitu-php.html. Diakses pada 1 januari 2020

[6] Davis, B.Gordon. (1985). Kerangka Dasar, Sistem Informasi Manajemen : Seri manajemen No. 90-A. Jakarta : PT Pustaka Binaman Pressindo

[7] Soemarwoto Otto, 2003, "Analisis Mengenai Dampak Lingkungan” Yogyakarta: Gajah Mada University Press

[8] Dr. Lilis Hermida, s.T. dan M.Sc. Dr.Joni S.T., M.Sc., (2016) “Perancangan Sistem Pengolahan Limbah Cair" Bandar Lampung : Anugrah Utama Raharja, hal 90

[9] A. S. Ahmadiyah, 2015. "Analysis and Design of Groundwater Quality Monitoring Application,"

[10] Widiyanto, AF. 2014b. Evaluasi Pengelolaan Limbah Klinis Tajam di RSUD Kabupaten Cilacap. Jurnal Kesmas Indonesia. Vol 6 No 32014. 